\title{
ANASTE Calabria Recommendations for the Treatment of Frail Elderly Diabetic Patients Hospitalized in Nursing Homes
}

Giovanni Sgrò*, Alba Malara, Grazia Francesca Renda, Giuseppe Curinga, Fausto Spadea, Vincenzo Rispoli, Francesco Ceravolo and Michele Garo

Scientific Coordination of National Association Structures Third Age (ANASTE) Section Calabria, Italy

\begin{abstract}
The prevalence of diabetes increases with age became higher in elderly and in patients admitted to nursing home. During aging, a functional reduction of the beta cell and increase in insulin resistance causes a greater risk in developing diabetes mellitus. It is also well known that association between aging and insulin resistance, recognizes a multifactorial origin. In elderly, both reduced physical activity and increase of visceral adipose tissue may play a causal role that it at least partly follows. Older adults with diabetes have higher rates of functional disability and sudden death, and concomitant diseases such as hypertension, coronary heart disease and stroke than those without diabetes. Older adults with diabetes are at increased risk for several common geriatric syndromes, such as polypharmacy and adverse reaction to drugs, depression, cognitive impairment, urinary incontinence, and persistent pain. In particular, the risk of macrovascular events is doubled and it is related to the duration of illness, the metabolic compensation and the number of other cardiovascular risk factors already present. Most of the elderly subjects in Long-term care (LTC) facilities are frail. The treatment of the elderly with diabetes is complicated by the heterogeneity of functional and clinical status. Life expectancy and the clinical conditions are highly variable. In these patients who take care of elderly people with diabetes must take this heterogeneity of account when establishing the priorities and goals of treatment.
\end{abstract}

Keywords: Diabetes; Fragility; Elderly; Nursing home

\section{Introduction}

The objective of the present paper is to provide recommendations for the management of patients hospitalized frail elderly admitted to nursing home, Extensive Rehabilitation, associated with ANASTE Calabria. The paper is based on reviewed literature on Cochrane analysis, consensus statements processed by other documents, opinions of experts.

\section{Epidemiology}

The number of elderly patients with diabetes mellitus is strongly growing. According to the most recent surveillance data, the prevalence of diabetes among U.S. adults aged $>65$ years varies from 22 to $33 \%$, depending on the diagnostic criteria used [1]. The prevalence of diabetes increases with age up to $18.9 \%$ in people aged $\geq 75$ years [2]. Diabetes is common in LTC facilities, with an overall diabetes prevalence of $25 \%$ [3]. The prevalence of diabetes mellitus was $27.5 \%$ in elderly patients in residential facilities associated ANASTE Calabria and the average age of patients with diabetes is 79.8 years [4]. The increase in the number of diabetic patients with age is consistent with the association of the aging processes to the decline in glucose tolerance and hence to an increased risk of developing type 2 diabetes $[5,6]$.

\section{Peculiarity of Type 2 Diabetes in Elderly}

The onset of diabetes in the elderly is overwhelmingly related to the decline of beta-cell function and the consequent decrease in insulin secretion both in basal conditions and in response to glucose [6-8]. It is also well known the association between aging and insulin resistance, recognizes a multifactorial origin. In the elderly, both reduced physical activity that increase of visceral adipose tissue that it at least partly follows may play a causal role [9]. It has recently been reported that a cause of insulin resistance in the elderly also increased triglyceride content of skeletal muscle tissue resulting in the decline of mitochondrial function, with reduction of oxidized physics and phosphorylation [10].

\section{Comorbidities}

In Italy $18.8 \%$ of people aged $\geq 65$ years have disabilities. The onset of disability is directly related to age, and ranges from $5.5 \%$ in the age group $65-69$ years to $44.5 \%$ in the age $\geq 80$ years, and $70 \%$ of older people with disabilities also has three or more chronic diseases [11,12]. In the United States diabetes is the sixth leading cause of death among the elderly. It has been estimated that patients with diabetes developed over the age of 65 have a reduced life expectancy of at least 4 years [13]. Older adults with diabetes have higher rates of functional disability and sudden death and concomitant diseases such as hypertension, coronary heart disease and stroke than those without diabetes. Older adults with diabetes have an increased risk for several common geriatric syndromes, such as polypharmacy and adverse reaction to drugs, depression, cognitive impairment, urinary incontinence, falls, and persistent pain [4]. The risk of macrovascular events, in particular, is doubled and is related to the duration of illness, the metabolic compensation and the number of other cardiovascular risk factors present [14].

The majority of elderly subjects in LTC are frail. The frail elderly may be defined as a person of advanced age, or very advanced, chronically suffering from multiple diseases, with unstable health, often disabled, in which the effects of aging and diseases are often complicated by socioeconomic problems [15]. Another feature of the elderly population living in LTC is the polypharmacy. In fact, it has been shown that these patients take an average of $6.87 \pm 5$ drugs [16].

*Corresponding author: Giovanni Sgrò, Scientific Coordination of Nationa Association Structures Third Age (ANASTE) Section Calabria, Italy, E-mail: giosgro68@gmail.com

Received June 06, 2013; Accepted August 14, 2013; Published August 16, 2013

Citation: Sgrò G, Malara A, Renda GF, Curinga G, Spadea F, et al. (2013) ANASTE Calabria Recommendations for the Treatment of Frail Elderly Diabetic Patients Hospitalized in Nursing Homes. J Gerontol Geriat Res 2: 128. doi:10.4172/21677182.1000128

Copyright: ( 2013 Sgrò G, et al. This is an open-access article distributed under the terms of the Creative Commons Attribution License, which permits unrestricted use, distribution, and reproduction in any medium, provided the original author and source are credited. 


\section{Glicemic Control}

The elderly diabetics, who have not physiological and cognitive disorders, with a good life expectancy, should be treated according to the same criteria used for young adults. For patients with advanced diabetes complications, concomitant diseases that limit life expectancy, substantial cognitive impairment or functional, it is reasonable to set less intensive glycemic target.

In the elderly patient with diabetes are recommended $\mathrm{HbAlc}$ values between 6.5 to $7.5 \%$ and a fasting glucose values of $90-126 \mathrm{mg} / \mathrm{dL}$. In frail elderly diabetic patients are recommended HbAlc values of 7.5 to $9.0 \%$ and fasting plasma glucose values of 126 to $160 \mathrm{mg} / \mathrm{dl}$ [4-17].

Glycemic goals for frail older people with functional and cognitive impairment, may be relaxed based on individual criteria, but symptomatic hyperglycemia or the risk of acute complications of hyperglycemia should be avoided in all patients.

The treatment of the elderly with diabetes is complicated by the heterogeneity of clinical and functional status. Some years before developing diabetes and may have significant complications, others who are newly diagnosed may have had years of undiagnosed diabetes, with complications that will arise from the disease. Some are frail and have other chronic conditions basic, consisting of comorbidities related to diabetes, or even a limited physical functioning and / or cognitive. Others have little comorbidity and are active. Life expectancy and the clinical conditions are highly variable. Who takes care of elderly people with diabetes must take this heterogeneity into account when establishing the priorities and goals of treatment. There are few longterm studies in the elderly show that the benefits of intensive glycemic control, blood pressure, and lipids.

The management of other risk factors provides a strong confirmation about the concept that comprehensive care for diabetes involves not only just hyperglycemia but overall treatment of each vascular risk factor.

The treatment of hypertension is virtually indicated in all older people, where as therapy with statins and aspirin can benefit those who have a life expectancy of at least equal to the period of time of the duration of studies of primary or secondary prevention. Screening for diabetes complications should be individualized in elderly adults; therefore special attention should be paid to complications which may lead to functional impairment [18]. There are no large trials of lipid-lowering interventions specifically in older adults with diabetes. A meta-analysis of 18,686 people with diabetes in 14 trials of statin therapy for primary prevention showed similar $20 \%$ relative reductions in major adverse vascular outcomes in those under compared with those aged $>65$ years [19].

\section{Hypoglycemia}

These patients are likely more exposed to suffer serious adverse effects from hypoglycemia. However the patients with poorly controlled diabetes may be subject to acute complications of diabetes, including dehydration, poor wound healing, and hyperglycemic coma and / or hyperosmolar. Glycemic targets should at least avoid these consequences. Particular care is required in prescribing and monitoring of drug therapy in the elderly. Treatment goals should be realistic, practical and explicit, with particular care to avoid hypoglycemic risk without jeopardizing the achievement of acceptable blood glucose levels [20].

In older diabetic subjects hormonal activation in response to hypoglycemia is attenuated, that is due to reduced glucagon response and is almost entirely supported by the secretion of adrenaline [21]. The counter regulatory catecholamine secretion may result in hemodynamic consequences and emerologiche with particularly negative effects on the brain and heart. On the other hand, the increased circulating catecholamine determines increased myocardial oxygen demand which can become critical in the presence impairment of coronary circulation. At this damage is associated thrombotic risk induced by adrenaline [22]. In elderly diabetics, therefore, hypoglycaemic episodes might be triggers of major cardiovascular and cerebrovascular episodes, such as myocardial infarction and stroke [20]. In subjects older than 70 years, hypoglycemia may occur with a set of symptoms not typical, characterized by weakness, faintness, unsteadiness, drowsiness, feeling light-headedness, difficulty in concentration. In addition, the very perception of symptoms is often attenuated, while we note the frequent occurrence of changes in motor coordination or joint report that simulate the clinical picture of an acute cerebral event [23,24]. During hypoglycaemia, loss of consciousness may lead coordination falls to the ground with traumatic injuries and fractures. Metformin is often contraindicated due to renal failure or heart failure significantly. The TZDs can cause fluid retention, which may exacerbate or lead to heart failure. These are contraindicated in patients with moderate and severe CHF (NYHA III-IV), and if used, must be with caution in patients with or at risk of milder degrees of CHF. Sulfonylureas, other insulin secretagogues and insulin may cause hypoglycemia.

\section{Lifestyle and Therapeutic Options}

Interventions designed to impact an individual physical activity level as well as food intake are critical parts in the management of type 2 diabetes. In LTC all every patient is included in programs of dietary interventions and physical activity compatible with the overall clinical condition. The diet should be controlled and contain fibre-rich foods such as vegetables, fruits, whole grains, legumes, low-fat dairy products, and fresh fish [25]. The choice of food must take into account the culture of the patients, preferences, personal goals, as well as abilities that can increase the quality of life, satisfaction with meals, and nutrition status [26]. Patients more frail, those with cognitive dysfunction especially, may have altered sensation of thirst, contributing to the risk of hypovolemia and hyperglycemic crisis; in fact, the fluid intake is encouraged, monitored and planned treatment [27]. Physical activity should be promoted as possible; ideally that should be aimed for at least $150 \mathrm{~min} /$ week of moderate activity [28]. On the other hand, a minimal tolerated physical activity is encouraged in complicated patients [29].

The drug should be initiated at the lowest dose and then increased gradually until the goals are achieved, without developing side effects. In addition, the elderly, screening for diabetes complications should be individualized. Particular attention should be paid to complications that may develop in a short period of time and / or which could significantly impair the functional state, as the visual complications and lower limbs.

The type 1 diabetic elderly should continue their insulin regimen. The multiple daily dosing regimens should be maintained even in old age, as it is the most secure even against hypoglycemia. Even a patient suffering from type 2 diabetes can be in conditions that require more or less stringent the use of insulin therapy.

The indications are: a) the presence of glucose values consistently high despite treatment and diet oral hypoglycemic agent, as frequently occurs for the progressive beta-cell depletion, commonly called "secondary failure", b) the existence of contraindications use of oral hypoglycemic agents in the presence of inadequate glycemic control 
with lifestyle changes alone, c) the presence of intercurrent disease. In elderly patients, insulin therapy should not be avoided but custom not to pay to achieve optimal glycemic targets with a hypoglycemic risk at acceptably high [30]. In most cases, the introduction of insulin in therapy is carried out with simplified diagrams, i.e. as a single injection of intermediate or slow insulin at bedtime to prevent hyperglycemia in the morning preferably. This scheme has its rationale only in patients who still exhibit a significant beta-cell secretory capacity with meals, allowing you to restore adequate blood glucose levels in the fasting state through inhibition of gluconeogenesis night. To reduce the risk of hypoglycemia while maintaining strict glycemic targets has been proposed using a regimen used as the basal insulin analogue glargine slow, peculiarly characterized by a slow-acting without peak. In a series of 426 patients with type 2 diabetes - age 40-80 years - in poorly controlled with oral hypoglycaemic therapy were randomized to therapy with insulin glargine vs. NPH bedtime, with no variation of the previous oral hypoglycemic therapy, it was observed that at the end of the 52 weeks of treatment the improvement of the compensation was similar in both groups, patients treated with glargine had values postprandial glucose better and a smaller number of hypoglycemic episodes especially at night [31].The group of patients treated with insulin glargine is also characterized by a lower weight gain [32]. A recent meta-analysis of randomized controlled trials involving the use of insulin glargine vs. NPH insulin in patients with type 2 diabetes has further shown a lower risk of nocturnal hypoglycemia with the use of insulin glargine [33]. Even with insulin glargine there is a rationale for combination therapy with oral hypoglycemics, chosen according to the patient's clinical phenotyping (metformin if there is more isulino resistance, if it prevails sulfonylurea insulin secretory deficiency). There is strong evidence that use of incretin therapy, in particular, the DPP-4 inhibitors, could offer significant advantages in older persons. Clinical evidence suggests that the DPP- 4 inhibitors vildagliptin and sitagliptin are particularly suitable for frail and debilitated elderly patients because of their excellent tolerability profiles [34].

Patients with type 2 diabetes solvents are characterized by the presence of a pre-prandial glycemic line down, so that the fasting blood glucose is higher at times of the day and the glucose nadir is observed before dinner [35]. Therefore it is dangerous to monitor, in these patients, insulin therapy using fasting plasma glucose only, even when the administration of a single injection of evening intermediate insulin or slow formulation with or without the oral hypoglycemic agents. The daily blood glucose profile should be recommended, with particular attention to measuring blood glucose before dinner. If a defect is documented beta-cell important, it is unrealistic to expect to achieve adequate control by requiring basal insulin associated with oral hypoglycemic agents only [36].

Therefore, even in elderly type 2 diabetic patients, the most rational therapy turns out to be the one with multiple insulin injections, done with rapid insulin before meals and bedtime intermediate insulin or with rapid acting analogues of insulin before meals and insulin glargine. The diagram fourfold administration is undoubtedly the most suitable to achieve the desired glycemic goals [37].

According ACCORD, ADVANCE, and VADT studies, about the $80 \%$ of frail patients obtain the best possible glicemic control with insulin therapy [38]. We must avoid that these patients would suffer the consequences of a delayed introduction of insulin therapy for the mere fact of being elderly (clinical inertia) [39].

In the majority of elderly patients with type 2 diabetes, who do not submit the correct indications, there are serious obstacles to the introduction of insulin therapy, which often improves the general state of health and life prospects [40]

\section{Appendix}

\section{Operating instructions on how to the management of diabetic fragile elderly patient}

Purpose: The purpose of this Operational Statement is to describe the management of the frail elderly diabetic patient entrance into the structure to its discharge with replacement home, if possible, to provide uniform procedures for all professionals involved, in order to make more effective and efficient intervention, and optimize resources.

Generality: The hospitalization of the elderly in Nursing Homes or Extensive Rehabilitation Center is according to the guidelines provided by the DGR 685/2002, DGR 695/2003, LR 29/2008, DGR 3137/1999. The need to ensure regularity in the management of a disease so highly in a very fragile group of patients resulted in the need to educate a systematized procedure.

Field of application: The requirements of this Operating Instruction apply to all functions and processes associated structures ANASTE Calabria. These procedures are valid until you change it, without prejudice to any provision of the medical facility according to specific health needs.

Description of activities: The day agreed with the patient and / or family, and / or other care setting, we proceed to the reception of new host and activate the various stages of recovery. The medical facility supported professional nurse, operator assistance, the rehabilitation therapist, psychologist and the social worker is moving in the medical and compilation of medical records. In the collection of the patient is checked for the presence of history of diabetes. In the subsequent medical examination are detected and physiological vital signs, including blood glucose measured capillary come with portable blood glucose meter. Are required blood tests for control, including blood glucose and glycosylated hemoglobin (HbAlc).

\section{Patient with no history of diabetes}

New diagnosis of Diabetes Mellitus: Evaluation of target metabolites: glucose, HbAlc, lipid profile, PA. Evaluation of the possible adherence to behavioral changes. Evaluation of adherence to drug therapy. Treatment as a function of HbAlc: HbAlc $\leq 7.5 \%$; HbAlc $>7.5$ and $<9 \%$; HbAlc $\geq 9 \%$. Levels of management in relation to assessment of clinical risk.

Patient with a history of Diabetes Mellitus: Evaluation of target metabolites: glucose, $\mathrm{HbAlc}$, lipid profile, PA. Evaluation of the possible adherence to behavioral changes. Evaluation of adherence to drug therapy. Treatment as a function of HbAlc: HbAlc $\leq 7.5 \%$; HbAlc $>7.5$ and $<9 \%$; HbAlc $\geq 9 \%$. Levels of management in relation to assessment of clinical risk.

Assessment of the fragility: VAOR (RUG III), ADL, IADL, CIRS, BARTHEL, MMSE, CDR, GDS, HAMILTON, CORNELL, ICF.

Clinical risk assessment: appreciation of the history and physical examination, laboratory tests, additional imaging studies, expert advice.

\section{Patient without additional clinical risk: clinical observation}

Patient with additional clinical risk: Assessment of target metabolites: glucose, $\mathrm{HbAlc}$, lipid profile, PA. Evaluation of the possible adherence to behavioral changes. Evaluation of adherence 
to drug therapy. Treatment as a function of $\mathrm{HbAlc:} \mathrm{HbAlc} \leq 7.5 \%$; $\mathrm{HbA} 1 \mathrm{c}>7.5$ and $<9 \% ; \mathrm{HbA} 1 \mathrm{c} \geq 9 \%$. Levels of management in relation to assessment of clinical risk.

\section{References}

1. Sue Kirkman M, Briscoe VJ, Clark N, Florez H, Haas LB, et al. (2012) Diabetes in older adults: a consensus report. J Am Geriatr Soc 60: 2342-2356.

2. Statistical Yearbook 2009, National Institute of Statistics (ISTAT).

3. Resnick HE, Heineman J, Stone R, Shorr RI (2008) Diabetes in U.S. nursing homes, 2004. Diabetes Care 31: 287-288.

4. Sgrò $\mathrm{G}$ et al (2011) HbA1c in the assessment of the metabolic compensation of a cohort of elderly patients in nursing homes. G Gerontol 59: 537

5. Shimokata H, Muller DC, Fleg JL, Sorkin J, Ziemba AW, et al. (1991) Age as independent determinant of glucose tolerance. Diabetes 40: 44-51.

6. Iozzo P, Beck-Nielsen H, Laakso M, Smith U, Yki-Järvinen H, et al. (1999) Independent influence of age on basal insulin secretion in nondiabetic humans. European Group for the Study of Insulin Resistance. J Clin Endocrinol Metab 84: 863-868.

7. Morley JE (2000) Diabetes mellitus: a major disease of older persons. J Gerontol A Biol Sci Med Sci 55: M255-256.

8. Shimizu M, Kawazu S, Tomono S, Ohno T, Utsugi T, et al. (1996) Age-related alteration of pancreatic beta-cell function. Increased proinsulin and proinsulinto-insulin molar ratio in elderly, but not in obese, subjects without glucose intolerance. Diabetes Care 19: 8-11.

9. Nilsson J, Jovinge S, Niemann A, Reneland R, Lithell H (1998) Relation between plasma tumor necrosis factor-alpha and insulin sensitivity in elderly men with non-insulin-dependent diabetes mellitus. Arterioscler Thromb Vasc Biol 18: 1199-1202.

10. Petersen KF, Befroy D, Dufour S, Dziura J, Ariyan C, et al. (2003) Mitochondrial dysfunction in the elderly: possible role in insulin resistance. Science 300 : 1140-1142.

11. Disability by age (2005) National Institute of Statistics (ISTAT).

12. Sgrò $\mathrm{G}$ et al (2009) Evaluation of the load of care in a group of elderly patients in nursing home. $V^{\circ}$ National Conference of Associazione dei Geriatri Extraospedalieri (AGE)

13. Gu K, Cowie CC, Harris MI (1998) Mortality in adults with or without diabetes in a National color of US population, 1971-1993. Diabetes Care 21: 1138-1145.

14. Meneilly GS, Tessier D (2001) Diabetes in elderly adults. J Gerontol A Biol Sci Med Sci 56: M5-13.

15. Fried LP, Tangen CM, Walston J, Newman AB, Hirsch C, et al. (2001) Frailty in Older Adults: evidence of a phenotype. J Gerontol Med Sci 56: 146-57.

16. Sgrò $\mathrm{G}$ et al. Polypharmacy and disability in the elderly. G Gerontol 2010; LVIII/6:480

17. European Diabetes Working Party for Older People 2001 - 2004. Clinical Guideline for type 2 diabetes mellitus. EUROAGE Diabetes. European Union Geriatric Medicine Society.

18. Basevi V, Di Mario S, Morciano C, Nonino F, Magrini N (2011) Comment on: American Diabetes Association. Standards of medical care in diabetes--2011. Diabetes Care 2011;34(Suppl. 1):S11-S61. Diabetes Care 34: e53.

19. Baigent C, Keech A, Kearney PM, Blackwell L, Buck G, et al. (2005) Efficacy and safety of cholesterol-lowering treatment: prospective meta-analysis of data from 90,056 participants in 14 randomised trials of statins. Lancet 366: 1267 1278.

20. Oiknine R, Mooradian AD (2003) Drug therapy of diabetes in the elderly. Biomed Pharmacother 57: 231-239.

21. Burge MR, Kamin JR, Timm CT, Qualls CR, Schade DS (2000) Low-dose epinephrine supports plasma glucose in fasted elderly patients with type 2 diabetes. Metabolism 49: 195-202.

22. Trovati M, Anfossi G, Cavalot F, Vitali S, Massucco P, et al. (1986) Studies on mechanisms involved in hypoglycemia-induced platelet activation. Diabetes 35: 818-825.

23. Thomson FJ, Masson EA, Leeming JT, Boulton AJ (1991) Lack of knowledge of symptoms of hypoglycaemia by elderly diabetic patients. Age Ageing 20 : 404-406.

24. Jaap AJ, Jones GC, McCrimmon RJ, Deary IJ, Frier BM (1998) Perceived symptoms of hypoglycaemia in elderly type 2 diabetic patients treated with insulin. Diabet Med 15: 398-401.

25. American Diabetes Association, Bantle JP, Wylie-Rosett J, Albright AL, Apovian $\mathrm{CM}$, et al. (2008) Nutrition recommendations and interventions for diabetes: a position statement of the American Diabetes Association. Diabetes Care 31 Suppl 1: S61-78.

26. Dorner B, Friedrich EK, Posthauer ME (2010) Practice paper of the American Dietetic Association: individualized nutrition approaches for older adults in health care communities. J Am Diet Assoc 110: 1549-1553.

27. Thomas DR, Cote TR, Lawhorne L, Levenson SA, Rubenstein LZ, et al. (2008) Understanding clinical dehydration and its treatment. J Am Med Dir Assoc 9 : 292-301.

28. Boulé NG, Haddad E, Kenny GP, Wells GA, Sigal RJ (2001) Effects of exercise on glycemic control and body mass in type 2 diabetes mellitus: a meta-analysis of controlled clinical trials. JAMA 286: 1218-1227.

29. Inzucchi SE, Bergenstal RM, Buse JB, Diamant M, Ferrannini E, et al. (2012) Management of Hyperglycemia in Type 2 Diabetes: A Patient-Centered Approach.Position Statement of the American Diabetes Association (ADA) and the European Association for the Study of Diabetes (EASD). Diabetes Care 35: $1364-1379$.

30. Cryer PE (2002) Hypoglycaemia: the limiting factor in the glycaemic management of Type I and Type II diabetes. Diabetologia 45: 937-948.

31. Yki-Järvinen H, Dressler A, Ziemen M; HOE 901/300s Study Group (2000) Less nocturnal hypoglycemia and better post-dinner glucose control with bedtime insulin glargine compared with bedtime NPH insulin during insulin combination therapy in type 2 diabetes. HOE 901/3002 Study Group. Diabetes Care 23: 1130-1136.

32. Rosenstock J, Schwartz SL, Clark CM Jr, Park GD, Donley DW, et al. (2001) Basal insulin therapy in type 2 diabetes: 28 -week comparison of insulin glargine (HOE 901) and NPH insulin. Diabetes Care 24: 631-636.

33. Rosenstock J, Dailey G, Massi-Benedetti M, Fritsche A, Lin Z, et al. (2005) Reduced hypoglycemia risk with insulin glargine: a meta-analysis comparing insulin glargine with human NPH insulin in type 2 diabetes. Diabetes Care 28: 950-955.

34. Abbatecola AM, Maggi S, Paolisso G (2008) New approaches to treating type 2 diabetes mellitus in the elderly: role of incretin therapies. Drugs Aging 25 : 913-925.

35. Trovati M, Ponziani MC, Massucco P, Anfossi G, Mularoni EM, et al. (2002) Blood glucose pre-prandial baseline decreases from morning to evening in type 2 diabetes: role of fasting blood glucose and influence on post-prandial excursions. Eur J Clin Invest 32: 179-186.

36. Hirsch IB (2004) Treatment of patients with severe insulin deficiency; what we have learned over the past 2 years. Am J Med 116 Suppl 3A: 17S-22S.

37. Hendra TJ (2002) Starting insulin therapy in elderly patients. J R Soc Med 95 $453-455$.

38. Skyler JS, Bergenstal R, Bonow RO, Buse J, Deedwania P, et al. (2009) Intensive glycemic control and the prevention of cardiovascular events: implications of the ACCORD, ADVANCE, and VA diabetes trials: a position statement of the American Diabetes Association and a scientific statemen of the American College of Cardiology Foundation and the American Heart Association. Diabetes Care 32: 187-192.

39. Phillips LS, Branch WT, Cook CB, Doyle JP, El-Kebbi IM, et al. (2001) Clinica inertia. Ann Intern Med 135: 825-834.

40. Reza M, Taylor CD, Towse K, Ward JD, Hendra TJ (2002) Insulin improves well-being for selected elderly type 2 diabetic subjects. Diabetes Res Clin Pract 55: 201-207. 